\title{
PREVENÇÃO E SUBJETIVAÇÃO: METAMORFOSES DA RELAÇÃO ENTRE TRABALHO E SEGURANÇA NA ITÁLIA'
}

\author{
Prevention and subjectivation: metamorphosis of the relationship between \\ work and safety
}

Vando Borghi ${ }^{2}$

\begin{abstract}
Resumo
0 tema da relação entre trabalho e segurança insere-se em um campo preciso de tensão, de fato circunscrito às fronteiras daquilo que foi definido como o paradigma da prevenção. Este campo de tensão está sendo submetido a uma metamorfose que transforma a sua articulação interna e o seu senso de totalidade. Ao colocar em foco a mutação que investiu sobre um fator fundamental do discurso público referente à relação entre trabalho e segurança, vale dizer as bases informacionais que o sugerem e que o alimentam, visamos compreender o sentido e a direção de tal metamorfose. Esta última se revela de fundamental importância, não apenas porque investe sobre o mundo do trabalho em sentido estrito, mas também sobre um terreno bem mais geral e, além disso, tornou-se fator fundamental da própria reprodução da lógica do capitalismo contemporâneo, vale dizer, do processo de subjetivação.
\end{abstract}

Palavras-chave: Relação entre trabalho e segurança; Prevenção; Subjetivação.

\begin{abstract}
The theme of the relationship between work and safety has to be placed in a specific field of tension, which is actually confined within the boundaries of what has been defined as the paradigm of prevention. This field of tension is in turn subject to a metamorphosis that transforms its internal articulation and overall sense. In focusing on the change that has invested a fundamental factor of the public discourse on the relationship between work and safety, namely the "informational bases" that support it and feed it, we will try to understand the meaning and direction of such metamorphosis. The latter is of crucial importance, since it invests not only the labor market in the strict sense, but also a much more general ground, which has also become a fundamental factor in the reproduction of the logic of contemporary capitalism, that is to say the process of subjectivation.
\end{abstract}

Key-words: Relationship between work and safety; Prevention; Subjectivation.

\footnotetext{
1 Este artigo é uma versão modificada do artigo publicado originalmente sob o título Prevenzione e soggettivazione: metamorfosi del rapporto tra lavoro e sicurezza em BORGHI, Vando, LEONARDIS Ota de e PROCRACCI, Giovanna. La Ragione Politica 2: $i$ discorse delle politiche. Napoli: Liguori Editore. 2013. Tradução do original: Attila Magno e Silva Barbosa.

2 Professor Associado do Departamento de Sociologia e de Direito da Economia da Universidade de Bolonha - Itália. E-mail: vando.borghi@unibo.it.
} 


\section{As bases informacionais do discurso sobre segurança e trabalho: uma breve "história do presente"}

A nossa reflexão tem como objetivo problematizar a relação entre segurança e trabalho e a manifestação desta no contexto das experiências de vida de cada indivíduo. Aqui, o termo problematizar refere-se precisamente ao modo como Castel (1994) - utilizando-se do trabalho de Foucault definiu eficazmente a análise sociológica que examina as relações entre a superficie do passado e a profundidade histórica dos elementos que a configuram. "A problematização - afirmava Foucault - não é a representação de um objeto preexistente, ou a criação por meio do discurso de um objeto não existente. É a totalidade das práticas discursivas e não discursivas que traz algo para o cenário do verdadeiro e do falso e as estabilizam como objeto para a mente" (CASTEL, 1994, p. 237-8). Ainda que a dimensão histórica desempenhe papel chave nesta específica prática-teórica de problematização, é o mesmo Castel a indicar que uma de suas características essenciais é que "os pontos de partida da análise e da orientação que a dirigem são a situação presente e o modo no qual a questão é formulada hoje” (1994, p. 238).

O objeto da nossa problematização é a relação entre as bases informacionais e o discurso público sobre a segurança do trabalho. $O$ discurso público se apresenta, seja rastreado ou investigado, em uma multiplicidade de formas e casos particulares. O que está em jogo é o teste das leis e das formas de regulação coletiva, dos contratos e das bases extracontratuais que tornam estes últimos efetivos e praticáveis (PERULLI, 2011), assim como os dispositivos e a moldagem operante no interior da "cidadania organizativa" determinada nos locais de trabalho pelas atividades de certificação, de padronização, de formação nos locais de trabalho, pelas informações estatísticas e assim por diante, ao mesmo tempo em que no entorno desta são incorporadas categoriais, classificações e estruturas de juízo sobre o significado de estar seguro. Este conjunto complexo se funde a um "estilo de pensamento", para recuperarmos a conceituação Fleck (1983), que "não concerne apenas a certa forma de explicação, o que seja explicar, mas se refere também ao que existe para se explicar" (ROSE, 2007, p. 12). As bases informacionais alimentam o (e, em um processo causal circular são 
alimentadas pelo) discurso público e, portanto, constituem parte integrante deste. A referência aqui é ao patrimônio conceitual do capability approach de Armatya Sen (2010), no qual o papel das bases informacionais como terreno crucial na determinação do processo de formação de decisões coletivamente vinculadas e, assim, como terreno factual do exercício de critérios de justiça, é tematizado e enfatizado (BONVIN; FAVARQUE, 2005).

Portanto, aquilo que segue é um esboço de problematização, isto é, de "história do presente" do modo como foi envolvida e transformada esta relação entre bases informacionais e discurso público sobre a questão da segurança do trabalho. Não uma reconstrução histórica sistemática e exaustiva, mas um aprofundamento das múltiplas possibilidades históricas (aquelas que prevalecem, aquelas minoritárias, aquelas possiveis, mas derrotadas) incorporadas na complexa trama do nosso objeto de análise (a relação entre bases informacionais e discurso público sobre segurança e trabalho), assim como este se apresenta nos dias atuais. Com tal propósito podemos identificar quatro fases históricas:

- Uma primeira fase pré-século XX, incluída entre: a) um primeiro período, da união da Itália até a metade dos anos 80 do século XIX, durante a qual o problema da segurança no nascente âmbito industrial é substancialmente ignorado; b) e um segundo período, da segunda metade dos anos 80, na qual o Estado introduz algumas formas mínimas de tutela (mais de fachada que substanciais), além disso, significativamente esvaziadas de significado ou frustradas (por ausência de força de imposição sobre os industriais e/ou de regulamento atuante e coerente). O clima ideológico e cultural que na fase precedente também tinha feito vã a introdução de formas mínimas de tutela (ao menos do trabalho juvenil), o segundo período que estava envolto na direção de um dominante maquinismo industrial e de uma "utopia tecnicista" que soldava e consolidava as muitas resistências políticas e culturais a este gênero de regulamentação e, mais em geral, a tudo aquilo que viesse a prejudicar os interesses dos grupos industriais. Tal quadro se confirma mesmo quando (1898) da promulgação de uma lei de tipo protetiva que, por mais avançada e 
exemplar que tenha sido, foi fortemente enfraquecida no sentido há pouco indicado;

- Uma segunda fase, a partir da primeira metade do século XX, que se caracterizou pela aprovação de um número muito mais encorpado de intervenções legislativas favoráveis aos trabalhadores e à tutela da saúde destes. A ascendente "questão operária", não só a crescente capacidade organizativa de um partido de classe e de um sindicato muito ativo, também forçou o Estado a tomar providências capazes de dar suporte às demandas sustentadas por uma forte onda de greves no início do século. Mais uma vez, no entanto, e não obstante a concretude de alguns resultados (a instituição do Escritório do Trabalho e do Conselho Superior do Trabalho), a utopia sócio-positivista que tinha contribuído para alimentar aquela temporada de avanços legislativos logo se exauriu e a utilização de motivos econômicos para mitigar os efeitos da nova legislação ajudou a enfraquecer o seu alcance. Em torno dos anos 50, contudo, a medicina do trabalho obtém uma crescente institucionalização, mas, no que concerne à nossa perspectiva de análise, tende a colocar em foco a questão das bases informacionais e da sua relação com o discurso público, acentuando um aspecto chave. Também em um quadro de reconhecimento institucional da medicina do trabalho, de fato, se confirma a separação persistente e sistemática entre sujeito (neste caso os saberes técnicos dos médicos e também dos estudos epidemiológicos e mais em geral do saber científico) e objeto (os trabalhadores, os quais são as condições e as experiências que são precisamente objeto destas pesquisas) do conhecimento e da produção das bases informacionais do discurso público sobre segurança do trabalho. Nessa fase, na qual a medicina do trabalho se insere em uma instalação meramente securitária de tutela da saúde nos locais de trabalho, emerge com toda clareza "a separação existente entre o fenômeno da saúde operária, como representado pelas doenças profissionais reconhecidas, e aquilo verificado por critérios diversos, seja como for, estes superam alguns limites convencionais postos pelo sistema securitário" (CARNEVALLE; BALDASSERONI, 1999, p. 152). Nesse contexto: 
indiretamente condições de nocividade transformavam-se em ocasiões de prevenção. A maior parte das vezes os trabalhadores permaneciam no escuro sobre os resultados dos estudos que thes interessavam [grifo do autor], os resultados circulavam, ao invés disso, tão somente no estreito círculo dos encarregados das pesquisas, os médicos, sem ao menos considerar outros técnicos, como executores e encarregados da segurança, que podiam caso fossem solicitados, iniciar ações capazes de corrigir ou eliminar as causas continuadas das doenças. O trabalho dos autores, em substância, permanecia no âmbito assistencial e previdenciário, confinado a uma estreita lógica securitária das doenças profissionais, e de qualquer modo, no interior da própria disciplina e do próprio papel profissional e técnico" (CARNEVALLE; BALDASSERONI, 1999, p. 154).

Nesse quadro, as bases informacionais e o discurso público que lhes atingem são fundados sobre uma rígida e marcada dicotomia entre o sujeito (o saber perito dos médicos) - que com esse conhecimento estabelecem códigos, critérios de pertinência, vocabulário, modalidades de classificação, escalas de prioridade, relações com as coisas práticas e assim por diante - e o objeto (os trabalhadores, as suas experiências e os seus conhecimentos), na sua dupla qualidade, de campo de observação sobre o qual aquele sujeito consolida e desenvolve o próprio saber perito e de destinatário dos efeitos diretos e indiretos do conhecimento produzido. Em ambos os casos, o objeto - vale dizer, as suas experiências de condições e de contexto de trabalho - é precisamente reificado no seu papel passivo, negado de qualquer competência, de qualquer capacidade de voz sobre o processo de produção e uso das bases informacionais e, portanto, feitos irrelevantes ou, de qualquer modo, marginais nas arenas nas quais o discurso público toma forma. A ênfase sobre este ponto não é excessiva; pois é exatamente sobre tal terreno, como se verá, no qual ocorrerão as principais transformações na fase sucessiva, que se tornarão profundas revisões (involuções?) na fase atual. Todavia, retornando ao período examinado, a relevância de tais bases informacionais e da modalidade de suas construções começa a tornar-se evidente nessa fase histórica e no momento entre 1952 e 1956 tomou corpo um novo enquadramento normativo e uma nova estrutura institucional a ele correspondente, a esse respeito, o movimento operário ressalta exatamente isto como os limites mais graves.

O trabalhador individual com base na nova norma tornava-se formalmente, com a garantia de sua saúde, credor das 'informações' provenientes do ofertante do trabalho sobre os fatores de risco presentes no local de trabalho. Porém, nada era dito sobre os direitos 
dos trabalhadores enquanto sujeito coletivo e organizado para participar da tutela da própria saúde e segurança (CARNEVALLE; BALDASSERONI, p. 199).

A consciência, de fato, da relevância do tema das bases informacionais e do modo como estas eram efetivamente constituídas crescia naqueles mesmos anos, não apenas nas organizações sindicais, mas também entre os trabalhadores; inquéritos, descrições detalhadas, relatos orais, documentações aprofundadas e assim por diante, começavam a sustentar os dados quantitativos coletados por médicos do trabalho, com uma intensidade que transcendia o âmbito restrito da questão da saúde do trabalho e que testemunhava a difusão de uma verdadeira e própria questão de justiça cognitiva (VISVANATHAN, 2009) no nosso país;

- Uma terceira fase, que coincide com "uma significativa mudança de paradigma na conceitualização da saúde", se estabelece "no decorrer dos anos sessenta, quando se superou a 'monetização do risco' para colocar no centro das intervenções de prevenção os trabalhadores" (DI NUNZIO, 2011, p. 25). Como veremos, emerge já nesta fase aquilo que constitui também no periodo seguinte, isto é, na fase atual, a moldura do discurso público, não apenas no que se refere à segurança no âmbito trabalhista, mas também à saúde de um modo geral, vale dizer, o paradigma da prevenção. Mas sobre isto, sobre as ambivalências de tal paradigma e sobre suas articulações e contradições internas, nos ateremos na segunda parte deste ensaio. Aquilo que já é importante aqui sublinhar, em relação a esta terceira fase, é a profunda transformação que se impôs naquele período (entre os anos $60 \mathrm{e}$ 70) sobre a construção das bases de informação e conhecimento do discurso sobre o trabalho e a saúde, uma transformação nos conteúdos e nos métodos que tiveram efeitos significativos de tipo global e estrutural. De modo esquemático, podemos assim sintetizar o aspecto de maior relevância: se realiza naquela fase um inédito processo de capacitação dos sujeitos (também) no âmbito da produção do discurso público; capacitação alimentada por meio do envolvimento dos próprios sujeitos na construção das bases informacionais (e, como consequência, das decisões coletivas).

Naturalmente é um processo pontuado por momentos de conflituosidade social, de contradições internas, de ambiguidades, mas que 
no seu conjunto promove uma crucial "ascensão geral" (LEONARDIS; BIFULCO, 2005) de experiências individuais e privadas; e assim, torna-se possivel tratar problemas de necessidade de segurança e de bem-estar como questões pertinentes à res publica e, portanto, enunciá-los no vocabulário dos direitos, promovendo um efeito que reverbera ainda hoje, no nosso presente. É nesta temporada e nesta passagem politico-cultural, além de científica, que, por exemplo, amadurecem as condições e ocorrem as experiências locais que constituem uma primeira experimentação para a realização do Sistema sanitário nacional. A centralidade da transformação do sentido e das modalidades de constituição das bases informacionais do discurso público aparece evidente na reconstrução histórica do percurso daquelas aproximadamente duas décadas. No início dos anos 60, sobre o impulso de um primeiro trabalho de investigação, realizado por Emilio Pugno, se constituiu um coletivo de pesquisa de operários, técnicos, sindicalistas e médicos do trabalho, liderados por Ivar Oddone, que investigou a saúde nos locais de trabalho e impôs uma hegemonia própria de definição do objeto e das práticas cognitivas para investiga-lo. O sucesso da imposição de um vocabulário próprio, novo e crítico para a definição, a leitura e para as ações relacionadas ao tema da saúde nos locais de trabalho, está ligado diretamente com as características do discurso público que estava sendo imposto.

O referido grupo consegue de fato exprimir um modelo político-técnico que traz vantagens "ao traduzir em frases simples e eficazes conceitos por vezes complexos, até fazer disso slogans como "a saúde não se vende", os "quatro grupos de fatores de risco", o "não delega", o "grupo homogêneo", a "validação consensual", às cadernetas sanitárias e de risco, os registros de dados ambientais e bioestatísticos”. O exercício da capacidade de voz - isto é, de protesto, mas também do mérito das questões em jogo e das palavras com as quais dizê-las - dos sujeitos que tinham experiências diretas nos problemas em questão, foi plenamente assumido pela CGIL (Confederazione Generale Italiana del Lavoro ${ }^{3}$ ) no conflito e nas negociações e favoreceu a constatação dos diretamente interessados de que "as condições de trabalho

\footnotetext{
3 Confederação Geral Italiana do Trabalho.
} 
não são 'objetivas', dadas de uma vez por todas, mas podem ser modificadas com efeitos apreciáveis também imediatamente" (CARNEVALLE; BALDASSERONI, 1999, p. 235). É significativo que, naquele período, um dos principais âmbitos disto que renomeamos aqui como processo de capacitação seja constituído para a introdução e para a realização da experiência das 150 horas. Espaço de valorização dos pontos de vistas dos diretamente interessados no processo de construção das bases informacionais e de conhecimento e, ao mesmo tempo, âmbito no qual vem consolidada e intensificada a "capacidade de aspirar4" dos trabalhadores, com efeitos significativos de interrogação e de inovação dos saberes codificados, as 150 horas representam o "terreno de confronto principal dos dois mundos, o científico e o operário" e introduzem o direito "inicialmente adquirido pelos trabalhadores metalomecânicos e químicos, de completar os seus processos escolares com as licenças obrigatórias, mas também de ampliar a própria capacidade de intervenção sobre a realidade de trabalho através de cursos monotemáticos desenvolvidos no coração dos mesmos lugares da produção cultural, as universidades" (CARNEVALLE; BALDASSERONI, 1999, p. 246-7). A insuficiência de normas em si e o envolvimento dos trabalhadores na produção das bases cognitivas e informacionais para o tratamento das questões da saúde e da segurança foi uma aquisição fundamental do grupo de pesquisa turinês, que representou, nas palavras de Accornero (1992, p. 138), “a única notável tentativa de renovação cultural" do sindicato. Na reconstrução histórica das "lutas pelo ambiente de trabalho", do pós-guerra aos anos 90, efetuada por Righi (1992, p. 629-30), esse momento chave com palavras que valem a pena citar diretamente, também porque evidenciam com clareza a relevância que atravessa as coordenadas temporais dentro das quais se origina:

Os trabalhadores, de fato, partindo das suas experiências, forneceram contribuições cognitivas originais à ciência médica; eles orientavam-se espontaneamente por uma avaliação epidemiológica das consequências do ambiente sobre a saúde, muito mais eficaz do que a medicina do trabalho tradicional, baseada essencialmente sobre nexos causais entre substâncias físico-químicas e patologias [...]. Através da redefinição do sujeito da pesquisa, procurou-se

\footnotetext{
4 Aqui nos referimos a uma conceituação proposta por Appadurai (2011), na qual a cultura é redefinida uma capacidade específica, isto é, o terreno no qual toma forma - ou menos - a possibilidade de imaginar um futuro mais digno e justo e de buscar praticá-lo já no contexto da vida presente. A "capacidade de aspirar" se alimenta assim da capacidade de voz e da experiência na qual os sujeitos conseguem "praticar o possivel” (DE LEONARDIS, 2011; DE LEONARDIS, DERIU, 2012).
} 
formular os traços de uma verdadeira revolução científica, suficiente para estar em condições de interpretar dados anteriormente ignorados pela medicina (como a percepção subjetiva da fadiga), e de prever um espetro mais amplo de fenômenos [...]. A valorização teórica da experiência operária também expôs em novos termos o papel dos intelectuais. Não se tratava apenas de difundir 'o' saber para quem não o tinha, mas de elaborar métodos e linguagens que permitissem uma comunicação entre universos cognitivos diferentes, superando visões espontaneístas de um lado e simplistas de outro. Malgrado os termos chaves deste léxico acentuassem acima de tudo a autonomia do grupo operário ('não delega' e 'validação consensual') - dando origem também a equívocos e contestações - o modelo inicial valoriza as especificidades as contribuições de ambos os componentes da pesquisa, mesmo que as modificando.

A consciência do potencial transformador derivante da expansão da capacidade de voz dos trabalhadores não era previamente presente e consciente, nem mesmo no sindicato, e esse aspecto "foi considerado por muito tempo apenas um instrumento mais eficaz de organização do consenso e não um recurso para a administração da crescente complexidade do ciclo produtivo" (RIGHI, 1992, p. 623-4). Todavia, a relevância dessa fase é evidente para a superação da monetização dos riscos para a saúde e o reconhecimento da participação dos trabalhadores na construção das bases cognitivas e informacionais do discurso público. Em jogo estão o vocabulário e a gramática que dão corpo a tais argumentações e o conflito "pelo monopólio da representação legítima do mundo social” (BOURDIEU, 1991, p. 12), que sobre o terreno de tal discurso se desenvolve. Em relação àquilo que está em jogo, revelam-se mais do que nunca emblemáticas as palavras de Trentin (1970, p. 257-8), na sua intervenção no Congresso Nacional da Federação dos Empregados Operários Metalúrgicos ${ }^{5}$ de 1970, para distinguir o "normal" trabalho sindical de denúncia de casos de insegurança e/ou nocividade e as mais ambiciosas produções de novas e diferentes bases informacionais do discurso público:

O conhecimento dos fatos, das suas consequências, o debate político sobre o alcance e as implicações de determinados fatores de nocividade em um dado departamento, em uma dada fábrica criaram a consciência da necessidade da luta não para ter uma identidade, mas para mudar as condições de trabalho e, se possivel, a fábrica. As comissões de inquérito que conquistamos em muitas fábricas podem tornar-se o instrumento para esta consciência coletiva; mas também, para além das comissões de investigação, coletivos de operários e de estudantes de medicina e de sociologia, podem

\footnotetext{
${ }^{5}$ FIOM - Federazione Impiegati Operai Metallurgici.
} 
elaborar, mesmo que com meios de informação aproximados de investigações de massa, uma comparação com os resultados das assembleias de trabalhadores na fábrica, levando estes resultados para fora da fábrica, associando a responsabilidade de todas as forças que podem ser mobilizadas para uma intervenção também externa; assim isolando diante da opinião pública aquele patrão que tentasse legitimar uma organização do trabalho que fosse regida sobre a mutilação da saúde e frequentemente sobre o risco para a vida dos operários. Isto é algo diferente da denúncia que nós fazemos, também quando nos referimos a dados estatísticos gerais, alguns impressionantes, mas ainda assim, abstratos, distantes da consciência das massas e, desse modo, sem chamar diretamente para o processo as responsabilidades e as escolhas de cada um. Trata-se de um salto de qualidade que nós nunca fizemos. Para mim parece determinante, se quisermos, como o afirmamos, trazer estes temas de fora da fábrica e recuperá-los com uma luta mais geral de reforma e transformação da sociedade.

- A quarta fase nos leva, enfim, a ocupar-nos do presente. Mas, como dissemos no inicio desta genealogia embrionária do modo como a "mercadoria que discute" (MORANDI, 1978) foi transformando a própria capacidade de voz sobre o terreno da saúde nos locais de trabalho, a "problematização" da realidade na qual estamos imersos, consiste propriamente na análise da história efetiva e potencial, que justamente no presente - como dado e horizonte de possibilidade - confluem. Isto é, se trata de fazer emergir e colocar às claras a interação entre as passagens acima referidas (sobretudo aquelas mais recentes), aquilo que reside nas dobras do presente, de uma parte, e o estilo de pensamento dominante que estabelece à autoridade e assim os critérios de pertinência, as formas de classificação, os códigos e os saberes peritos que o inervam, da outra. Se já na terceira fase de nossa periodização emerge o paradigma de prevenção, que bem caracteriza também o nosso atual horizonte de experiência (PITCH, 2008; CARNEVALLE; BALDASSERONI, 1999; DI NUNZIO, 2011; GOSETTI, 2012), é necessário então entender a pluralidade das articulações internas de tal paradigma, rastreando a evolução das relações entre estas diferentes articulações e explicando as diferentes temporalidades que são sempre coexistentes e incorporadas em um fenômeno social ${ }^{6}$ e que uma investigação destinada à "problematização" deste fenômeno deve fazer emergir.

\footnotetext{
6 Sewell (2008a, 2008b) identifica três temporalidades que estruturalmente atravessam os fenômenos sociais e, portanto, devem ser investigadas para compreendermos os seus significados atuais: aquelas que se referem às condições estruturais de longuissimo prazo; aquelas referentes à história
} 


\section{O discurso da prevenção: gênese e mudança}

O alcance das transformações que identificamos na terceira fase de nossa periodização foi salientado para além do âmbito circunscrito da segurança do trabalho. No seu Storia della medicina e della sanità nell'Italia contemporânea, Cosmacini (1994) destaca como a atenção aos temas da poluição da água e do ar e, em geral, da salubridade no ambiente urbano, derivam de fato de uma extensão da consciência da saúde adquirida nas fábricas nos anos 60 e 70. Impõe-se naqueles anos uma concepção da saúde que veio a dar corpo a um paradigma de prevenção mais geral e transversal. É esse paradigma que alimenta algumas das transformações sociais e institucionais mais significativas da nossa sociedade, e cujos efeitos são claramente encontrados em diversos institutos (em um sentido sociológico e mesmo antes administrativo) da nossa vida coletiva, fazendo a prevenção configurar-se "assim como um objetivo e um motor fundamental da pesquisa científica como reforma social” (PITCH, 2008, p. 40). Mas, faz-se necessário dizer que a "modalidade prevalente das práticas e politicas de prevenção" que emerge naqueles anos e que se consolida e institucionaliza nas décadas seguintes, é "uma modalidade precisamente social, coletiva e pública". São as instituições que dão suporte à prevenção, bem mais que os indivíduos, conduzindo-se em direção de riscos sociais consideráveis, a começar pelas causas das doenças (...): "o ethos prevalente guia-se pelos confrontos daquilo que é coletivo e social, sendo que são precisamente, em grande parte, as instituições que lhe dão suporte" (PITCH, 2008, p. 40-1). Os indícios e traços sobre os quais chamaremos atenção, como os que emergem da análise desenvolvida no ensaio de Giullari, Rizza e Sansavini (2013), fazem pensar, em vez disso, uma mudança no estilo de pensamento no qual este paradigma é interpretado e a implantação de mecanismos discursivos orientados para a ativação de outros cursos de ação.

O que de fato parece delinear-se com certa clareza é um processo de transformação de um paradigma fundador do discurso público da prevenção. Depois de ter colocado o percurso de sua emergência em foco -

conjuntural de vazão temporal média; e aquela dos eventos decorrentes de "ações estratégicas ou voluntárias contingentes". 
resumidamente na passagem da monetização do risco da institucionalização da prevenção (no campo da segurança do trabalho), tentemos agora interpretar os traços e sintomas correntes da profunda transformação que atualmente o caracterizam. Naturalmente se trata de um quadro social complexo, articulado, ambíguo e ambivalente, no qual coexistem, por vezes conflituosamente, lógicas e práticas atribuiveis aos estilos de pensamento pertencentes às diferentes fases da transformação. Encontramos traços dos diferentes estilos de pensamento no mesmo aparato de regulamentação jurídica do campo atualmente vigente (o chamado Texto Único sobre Saúde e Segurança). Mas, é da análise do conjunto social em questão (que não se exaure no plano do texto da lei), da investigação do modo como essa coexistência de lógicas argumentativas e sociais atravessa o estilo de pensamento e os mecanismos do discurso sobre a segurança e se manifesta na experiência dos diversos sujeitos que é possivel compreender o significado das transformações em curso.

Em termos extremamente esquemáticos: o campo da segurança é atravessado por uma tensão, que penetra também os dispositivos (padrões, alvos, sistemas de certificações, etc.) que nele operam e ao mesmo tempo constituem as bases informacionais que alimentam o referido campo e a sua tensão; uma tensão que flui entre duas polaridades em torno das quais o discurso público vem adensando-se no tempo. De um lado, se delineia uma polaridade do discurso ancorada em uma concessão residual: segurança como ausência de risco mais ou menos grave, como requisito funcional à plena e eficiente relação de uma performance produtiva e organizacional, performance no qual a lógica intrínseca não é de modo algum condicionada ou condicionável pelos objetivos da segurança, sendo esta última, quando muito, uma execução (burocrática) à cumprir; do outro lado, uma polaridade que faz, ao invés disto, referência a uma concessão de segurança como direito à saúde nos locais de trabalho e de saúde como bem-estar psicofísico, como reconhecimento da integridade e da dignidade dos indivíduos, na qual a definição concreta (geral e localizada) e o aprendizado prático dos sujeitos envolvidos devem poder participar ativamente. Neste segundo caso, a segurança torna-se parte de um trabalho (não de um trabalhador) do qual se 
faz cuidado, de um bom trabalho, de uma compreensão global do fazer bem e com qualidade as coisas e de tomar cuidado no trabalho, no ambiente circundante e naquilo do qual este é feito, se trata dos aspectos materiais e imateriais. Essas duas polaridades animam, por conseguinte, dois modos de recusa no discurso, nos direitos, na saúde e nas relações que devem ser respeitadas entre estas (no que concerne ao nosso caso, no âmbito do trabalho). Tentemos então retomar alguns dos sintomas mais significativos da transformação que, no campo de tensão aqui circunscrito, aparecem atualmente em curso.

\section{a. Sintomas e indícios linguísticos: em direção a uma neo-lingua?}

Como com certa frequência ocorre, a linguagem representa o terreno no qual mais precocemente é possivel encontrar os traços de uma transformação profunda na qualidade dos processos sociais. Na linguagem, de fato não está simplesmente em jogo a produção de formas simbólicas que exaurem os seus feitos sobre o plano da comunicação. Em vez disto, é propriamente o funcionamento dos dispositivos do discurso que ativa os cenários plausíveis para ação e contribuem para a construção de "regimes de verdade", de acordo com práticas que têm consequências muito concretas: "o governo de uma 'economia' torna-se possivel apenas graças a mecanismos discursivos que representam o governar como inteligivel, com as suas fronteiras e características e com componentes ligados mais ou menos de maneira sistemática" (ROSE, 2007, p. 33). Os "mecanismos discursivos" que de fato redefinem e reinterpretam o paradigma da prevenção, abrem um espaço para mapear, classificar, teorizar, transformar em objetos de pesquisa, de investimento, de busca por vantagens competitivas. Não é tanto uma questão de distorção de uma linguagem, de alguma forma compartilhada: "É mais uma questão de produção e configuração da verdade do que de fabricação e marketing da mentira" e é em relação a este mesmo processo que a biopolítica, da qual também o paradigma da prevenção é parte integrante, "torna-se bioeconomia" (ROSE, 2007, p. 32). Novos termos, acrônimos, expressões de jargão técnico que fazem parte hoje do senso comum, novos usos de palavras familiares, expressões inéditas (e seja quem 
for que tenha se aventurado no campo da segurança do trabalho, pode constatar a maciça presença de tudo isso): o emergir de uma verdadeira e própria neolingua sinaliza frequentemente que está em curso uma mudança que se manifesta em primeiro lugar nos modos de recortar as janelas linguísticas de acesso à experiência do mundo, mas que, em um modo mais estrutural, tem a ver com transformações epistêmicas do modo como as formas de conhecimento do mundo ativam determinados cursos de ação e outras emergem ou são interditadas. O deslizamento de determinados termos de um âmbito linguístico para outro de fato não é nunca privado de efeitos: a linguagem de uma esfera linguística e social específica "pode também eclipsar, sufocar, 'colonizar' o contexto de chegada" (PÖRSKSEN, 2011 , p. 136). Sobretudo, onde prevalece a linguagem abstrata dos especialistas produz-se um efeito de desabilitação particularmente intenso dos cidadãos e dos trabalhadores (ILLICH et al, 2008): de um lado, tal linguagem "torna o mundo planificável e o aplaina em um modo que possa ser projetado com o tecnígrafo"; do outro, "serve para esconder a realidade", impedindo "à imaginação de ter um papel na vida das pessoas" e ignorando o que estas "vivem e sentem, as suas histórias de vida" (PÖRSKSEN, 2011, p. 149).

Para exemplificar esse quadro, podemos nos servir de dois indícios contidos nos materiais de pesquisa de campo. O primeiro representado pelo termo 'dispensa': eixo de conexão entre a dimensão pública (os códigos de leis) e a privada (as formas de certificação voluntária), ele ativa e institui uma fronteira invisível, mas com consequências concretas sobre o campo da segurança. Por dispensa, entenda-se uma meta a cumprir de formalidades e procedimentos, a qual, uma vez formalmente certificada, resguarda a empresa e os seus atores de eventuais consequências em caso de acidentes. Trata-se de um verdadeiro e próprio processo de ativação de cursos de ação (WEICK, 1997), desencadeado por dispositivos do discurso público, sob a forma de decreto legislativo, com efeitos significativos consistentes, de fato, na promoção de uma série de "rituais de verificação" (POWER, 2002) padronizados que, como exemplifica os dois temas de entrevista aqui reportados, não implicam um efeito sobre segurança do ambiente de 
trabalho, mas sim, uma proteção de eventuais consequências para quem é responsável pelas atividades realizadas nesse mesmo ambiente.

\begin{abstract}
"existe um grande mercado referente ao $18001^{7}$, por isso do texto único, de 15 de maio de 2008, o interesse cresceu: agora dizer que neste exista uma motivação ética é uma mentira, quem sabe existe e em alguma empresa seguramente é verdadeiro, porém na maior parte, portanto a grande massa da qual nos fazem pedidos de certificação, existe o interesse da isenção da responsabilidade administrativa [...] Nós vamos avaliar um sistema de gestão que se implementado e mantido pode ser eficaz para a isenção 231, portanto, você entende que, se o sistema for certificado, nós somos um ator importante nesse procedimento, então, antes do artigo 30 na verdade a certificação da segurança não era assim tão pesada para uma entidade de certificação, um pouco porque havia pouco mercado e um pouco porque não havendo a isenção, era um sistema como tantos outros [...] Assim, mudou muito o papel das entidades de certificação porque nós podemos ser chamados para testemunhar em um processo sobre responsabilidade administrativa e não apenas, podemos ser chamados também durante as investigações. Como entidade de certificação, nós temos três óbitos em empresas clientes nossas certificadas sob aprovação, nós estávamos situadíssimos, nós estávamos dentro das regras de aprovação, estão agora em curso as investigações, porém nos saímos bem disso, nós e os nossos clientes porque durante as investigações se está entendendo que a responsabilidade provavelmente era do seu comitente" (Sociedade de Certificação responsável).
\end{abstract}

$\mathrm{Na}$ cena "em empresa nossa cliente certificada" "ocorreram três óbitos", mas "nos saímos bem disso, nós e o nosso cliente", existem claros elementos que remetem àquilo que Leonardis e Giorgi (2013) observam a propósito dos truques argumentativos através dos quais se produzem realidade fictícia. Uma oferta de realidade fictícia que produz a própria demanda: o risco de que seja criado um "mercado impróprio", que responde à pergunta "onde se compra à isenção?", emerge com evidência no curso da investigação. Vários interlocutores registram, a esse proposito, aquilo que tecnicamente se define "efeito de transposição dos fins" (SCOTT, 1992), com base no qual quanto mais se intensifica a ênfase sobre os meios e procedimentos (formais), tanto menos se busca substancialmente o objetivo da adoção daqueles instrumentos:

"Dou este exemplo: quando um funcionário de fiscalização vai a uma empresa ver como estão aplicando a norma, a 626 ou a 81, vão lá e dizem, tendo um checklist, "me mostre o atestado de que o representante dos trabalhadores para a segurança fez o curso?", tem

\footnotetext{
7 O OHSAS 18001 é uma série de normas desenvolvidas pelo British Standards Institution Group para orientação e formação de um Sistema de Gestão e certificação da segurança e saúde ocupacionais, visando definir uma padronização de requisitos mínimos para melhores práticas em gestão de saúde e segurança ocupacional.
} 
também, "me mostre o curso contra incêndios? Esta é toda a loucura, toda a loucura, que deveria ser alterada para este modo: o inspetor entra na empresa e diz "me mostre como vocês estão organizados para a segurança" [...] Quero ver como vocês estão organizados, como vocês estão fazendo a aplicação, entrar no verdadeiro coração do problema, não apenas no papel, este é o erro que hoje se arrasta porque aqui o discurso torna ainda mais perverso, porque aqui entra em jogo também o poder judicial, porque aqueles que se ocupam da fiscalização estão submetidos a interpretação dos juizes, isto é, eles veem os tribunais e as causas que o juiz quer ver o certificado, se não há nada de certificado, se julga em função disto, também lá o juiz não vai ao coração do problema, "tenha o atestado, tudo bem", por isso existe todo esse discurso da necessidade de uma mudança profunda, se queremos fazer crescer a segurança devemos mudar o modo de ver as coisas, agora as vemos desse modo aqui, vamos ver se vocês prepararam os papeis e não se a organização foi criada" (ex-responsável de segurança de uma grande empresa, atualmente responsável de área de segurança em uma entidade de formação e consultoria).

Um segundo indício ainda mais evidente devido à importância com a qual este tema é recorrentemente tratado na publicidade do setor e a ênfase que é colocada sobre a sua precisa e quantitativa mensuração em todas as organizações, é aquilo que tem a ver com o stress relacionado ao trabalho. Neste sentido, parece bastante apropriado quando afirmado pelo estudioso da organização do trabalho Ives Clot, sempre que ele destaca como também o tema do bem-estar psicossocial tem sido adiado, da questão do tratamento dos conteúdos e das formas do trabalho, à questão da responsabilidade individual na cura de si mesmo. "É um pouco como se abrissem, nas empresas, em matéria de saúde mental do trabalho, "alguns corredores humanitários" sobre os terrenos das "guerras econômicas". É de fato, a mesma função, escreve Clot (2011, p. 41) dos planos de ação contra os riscos psicossociais: adicionar à gestão dos riscos aos riscos da gestão, estendendo ainda mais o campo do gerenciamento à engenharia psicológica. Sobre este caminho, é o stress dos trabalhadores que é necessário tratar, enquanto é o trabalho que está doente, porque aos trabalhadores é impedido de arcar com o tratamento". Como assinala Salento (2013), da atribuição que assume a organização do trabalho, as empresas e as organizações em geral, como entidades dadas, como caixas pretas das quais os conteúdos e da qual a racionalidade não são discutidos, resulta de modo complementar a ideia "de uma atribuição propriamente psicológica-individual do denominado stress relacionado ao trabalho, e de uma ênfase sobre os denominados riscos 
psicossociais, tudo orientado para tratar o mal-estar do trabalho como malestar do trabalhador".

Em um contexto internacional do aumento de atenção, também cientifica, da dimensão psicológica e das questões do bem-estar e da saúde associadas a essas dimensões, em outubro de 2004, as partes sociais europeias (sindicatos e empresas) assinaram um Acordo Quadro ${ }^{8}$ sobre stress relacionado ao trabalho que foi transposto para a Itália em junho de 2008. Acordo bastante genérico na definição do próprio objeto, das causas que estariam na origem deste e da metodologia para abordá-lo, isto produziu em alguns países uma forte discussão sobre as maneiras de interpretá-lo e de torná-lo operacional. Em uma circular do Ministério do Trabalho e da Politica Social9 ${ }^{9}$, divulgada não apenas nos canais oficiais, mas com bastante frequência ligada às empresas privadas e de suas propostas de cursos econômicos e de atividades para cumprir as obrigações legais (se vê, por exemplo, o texto expedido recentemente para milhares de escolas com as quais uma empresa privada, acompanhando-a com a circular citada, introduzia a própria proposta e o respectivo tarifário): "a avaliação preliminar" do risco do stress, obrigatória para todos, é identificada pelo "reconhecimento de indicadores objetivos e verificáveis, sempre que possivel, mensuráveis".

\section{Caro gestor acadêmico,}

Como certamente o senhor recordará, nos termos do Decreto Legislativo $81 / 2008$, a instituição dirigida pelo senhor deve realizar uma avaliação do risco do stress relacionado ao trabalho junto a todos os funcionários (corpo docente e corpo de auxiliares técnicos administrativos, bem como junto aos estudantes em atividade de laboratório).

Em caso de não cumprimento estão previstas sanções pecuniárias e penais sobre sua responsabilidade pela inadimplência da normativa de segurança do local de trabalho (626 e modificações sucessivas). Poderá verificar o que foi dito por meio da secretaria ou simplesmente consultando a internet.

\footnotetext{
$8 \mathrm{Na}$ União Europeia é um tipo de contrato público que visa disciplinar relações contratuais futuras. É uma ferramenta de negociação que estabelece as regras relativas aos contratos a serem celebrados durante um periodo máximo de quatro anos.

9 A referida cicular "ordena as aprovaçãos das informações necessárias de avaliação dos riscos do stress relacionado com o trabalho contidas no artigo 28, parágrafo primeiro do Decreto Legislativo n. 81 , de 09 de abril de 2008, e respectivas alterações e aditamentos subsequentes".
} 
A nossa empresa - sobre a qual poderá obter informações no site www.etc, onde encontrará uma cópia da normativa e das principais interpretações jurídicas - está em condições de fornecer-lhe os instrumentos de execução, quando solicitado pela lei, dentro de 30 dias da subscrição da tarefa, que pode ser confiada diretamente por uma modica quantia.

Os custos variam entre 170 e 850 euros além do imposto sobre valor acrescido, a segunda em termos adicionais ao seu instituto. Caso haja interesse de sua parte ou para maiores informações the peço para contatar-me no seguinte endereço (...).

Desculpe-me à brevidade e o tom deste e-mail, mas devemos adverti milhares de escolas em poucos dias, e infelizmente faz-se necessário pô-los a par das obrigações jurídicas imediatamente.

Roma, 29 de setembro de 2010.

Cordialmente, (Responsável pela área de Marketing XXX)

Figura I. Proposta econômica relativa à avaliação do stress relacionado ao trabalho.

No âmbito institucional (à exemplo da escala regional), em um contexto geral que segue na mesma direção da chamada ênfase nos dados objetivos e quantitativos, isto conduziu, principalmente, à formação de Comissões e grupos de trabalho para definição, operação e reconhecimento desses indicadores (em organizações como a Administração Pública, as estruturas de saúde e outras mais), compostas quase que exclusivamente de especialistas do campo médico, psicológico e da engenharia. Também nas empresas, frequentemente, esse dispositivo discursivo - o stress relacionado ao trabalho - ativou cursos de ação que vão exatamente à direção oposta em relação àquela capacitação dos trabalhadores que também, a respeito destas mesmas problemáticas, tinha-se afirmado em outra fase do processo histórico-social que estamos investigando. É uma consideração que se impõe ainda mais sempre que se colocam em comparação as indicações da diretiva europeia, na qual se previa um envolvimento efetivo dos trabalhadores e das suas representações, com os conteúdos da Linha Guia indicados na circular já citada - que diz o seguinte: "nas empresas de maior tamanho é possivel ter uma amostra representativa de trabalhadores. A escolha das formas através das quais se escuta os trabalhadores é atribuida ao empregador, assim como da metodologia de avaliação adotada" (grifo do autor) - e, acima 
de tudo, da metodologia de avaliação adotada, com a qual estas são então interpretadas pelos atores que trabalham no campo da segurança. A esse respeito, as considerações que se seguem, coletadas no decorrer da pesquisa, são significativas:

\begin{abstract}
"As dificuldades existentes referem-se ao âmbito no qual trabalhamos, isto é, a Fiat, porque a Fiat coloca algumas regras da empresa que às vezes, para a RSPP10 em particular, são superiores à lei 81 e ao contrato nacional de trabalho. Por exemplo, sobre o stress relacionado ao trabalho, a empresa tinha obrigação até o prazo de 31 de dezembro do ano passado para efetuar a avaliação sobre o stress relacionado ao trabalho, e não obstante já existissem algumas linhas guias sobre como aplicar a avaliação propriamente e todo o resto, houve uma circular Fiat que dizia essencialmente que a avaliação devia ser feita pela RSPP com o médico competente, com a direção de pessoal e ponto final, por isso os RTS ${ }^{11}$ representantes de segurança dos trabalhadores não foram minimamente envolvidos, não houve uma consulta prévia, nada de nada (...) Não foi difícil apenas, como dizer, colocar em apreciação o stress relacionado ao trabalho foi dificil apenas, não obstante fosse uma obrigação legal, isto é, levamos um ano e meio somente para convencer a empresa e a RSPP que não podiam fazer o seu documento de avaliação de risco e pronto, sem envolver não apenas os trabalhadores, mas sem se quer pensar em envolver os RTS. Na primeira elaboração que foi feita, eles não consultaram para isto nem mesmo os representantes, apanharam o checklist, responderam eles mesmos todas as perguntas, nível de risco baixo, acabou ali (...). Passamos um ano e meio escrevendo cartas, ameaçando de fazer uma intervenção da Agência de Saúde Local, se não pior, para obriga-los a retornar a mesa e refazer junto conosco RTS um pouco de toda a avaliação em questão, e refazendo-a juntos chegamos ao limite da faixa média de risco. Porém, também aí, até que se leve em consideração o checklist genérico que às vezes não têm haver com nada daquilo que vivemos na fábrica, é um pouco como enganarmos uns aos outros (Representante dos Trabalhadores para Segurança (RTS) em um dos casos empresariais investigados no decorrer da pesquisa).
\end{abstract}

\title{
b. As ciladas da individualização
}

A individualização representa há muitos anos a matriz argumentativa a partir da qual são legitimadas e introduzidas profundas transformações das políticas e dos serviços públicos. No âmbito da União Europeia tem sido através de argumentações centradas na promoção (moral e material) do indivíduo autônomo e responsável que são criadas as condições de um

\footnotetext{
10 De acordo com o estabelecido pelo Decreto Lei 81/2008, dentro de uma empresa é necessária a presença de um Responsável pelo serviço e proteção (RSPP). Esta figura, nomeada pelo empregador, deve possuir as quailificações adequadas para avaliar a natureza dos riscos presentes no local de trabalho, a fim de assumir e mostrar ter as responsabilidades que lhes permitam organizar e gerir todo o sistema referente à prevenção e protecção dos riscos. A função RSPP também pode ser exercida pelo empregador, no caso de empresas: artesanais ou industriais, com até 30 funcionários; pecuária e agrícola, que empregam até 10 funcionários; psicultura, com um limite de 20 trabalhadores; outras áreas, até 200 empregados.

11 Representantes dos trabalhadores para segurança.
} 
deslizamento semântico do trabalho - como responsabilidade coletiva e como resultado de processos de organização e coordenação social - à empregabilidade - como propriedade dos indivíduos e de suas capacidades ou ao menos de fazer valer o próprio "capital humano"; e é neste quadro que foram legitimadas e introduzidas politicas de ativação e são impostas revisões dos serviços (e da condicionalidade destes), por sua vez modelados dentro do molde dos princípios e das tecnologias administrativas da New Public Managment (VAN BERKEL; WALKENBURG, 2007; BORGHI; VAN BERKEL, 2007a, 2007b).

No que se refere às relações entre segurança e trabalho é possivel observar de perto o modo como o mecanismo discursivo da individualização opera sobre o paradigma da prevenção. Emerge uma profunda ambivalência que parece caracterizar o efeito de reinterpretação da prevenção: de um lado, fica evidente o registro da responsabilização, da moralização, culpabilização ou, de qualquer modo, de colocar os indivíduos à prova, que opera através do deslizamento da tarefa (de perseguir a prevenção, de produzir a segurança) da coletividade, das organizações e das estruturas sociais e institucionais, para o indivíduo e para o terreno da experiência privada; do outro, como fica evidente nos exemplos do tratamento do stress relacionado ao trabalho e da adoção do dispositivo organizacional discutido no próximo parágrafo, o registro da responsabilização é complementar às práticas e aos procedimentos de desresponsabilização dos indivíduos (desindividualização?), com os quais a segurança (e a avaliação da responsabilidade que os indivíduos possuem sobre as ações de criar e enfraquecer as suas condições de realização) retira de fato a capacidade daqueles que possuem experiências relacionadas ao problema; capacidade que tinha sido em oposição ao terreno privilegiado daquele processo (de capacitação, precisamente) que vimos caracterizar a terceira fase da nossa periodização. A partir deste segundo efeito, a segurança coincide cada vez mais especificamente com o cumprimento formal e mecânico dos objetivos incorporados em metas e limites preponderantemente quantitativos e padronizados, dados em princípio definidos de fora e acima de qualquer capacidade de intervenção dos indivíduos aos quais são endereçados. 
Voltando ao tema em questão (a distorção paradoxal da individualização): coerentemente com a lógica do discurso plenamente destacado no livro branco do Ministério do Trabalho e das Políticas Sociais italiano, publicado no mesmo período da realização da pesquisa que serviu de base para este artigo, (BORGHI, 2009). A interpretação do paradigma da prevenção na chave moral da responsabilização (ou não) dos indivíduos emerge com toda a clareza na campanha publicitária sobre segurança e trabalho, caracterizada pelo slogan: "Segurança no trabalho: uma exigência de quem se quer bem". No informe governamental que segue abaixo temos uma família na qual o pai é um diretor de obras e a mãe uma enfermeira. Na folha de notas que aparece na imagem tem-se o seguinte dizer: "faça com que esse momento não seja apenas uma lembrança”.
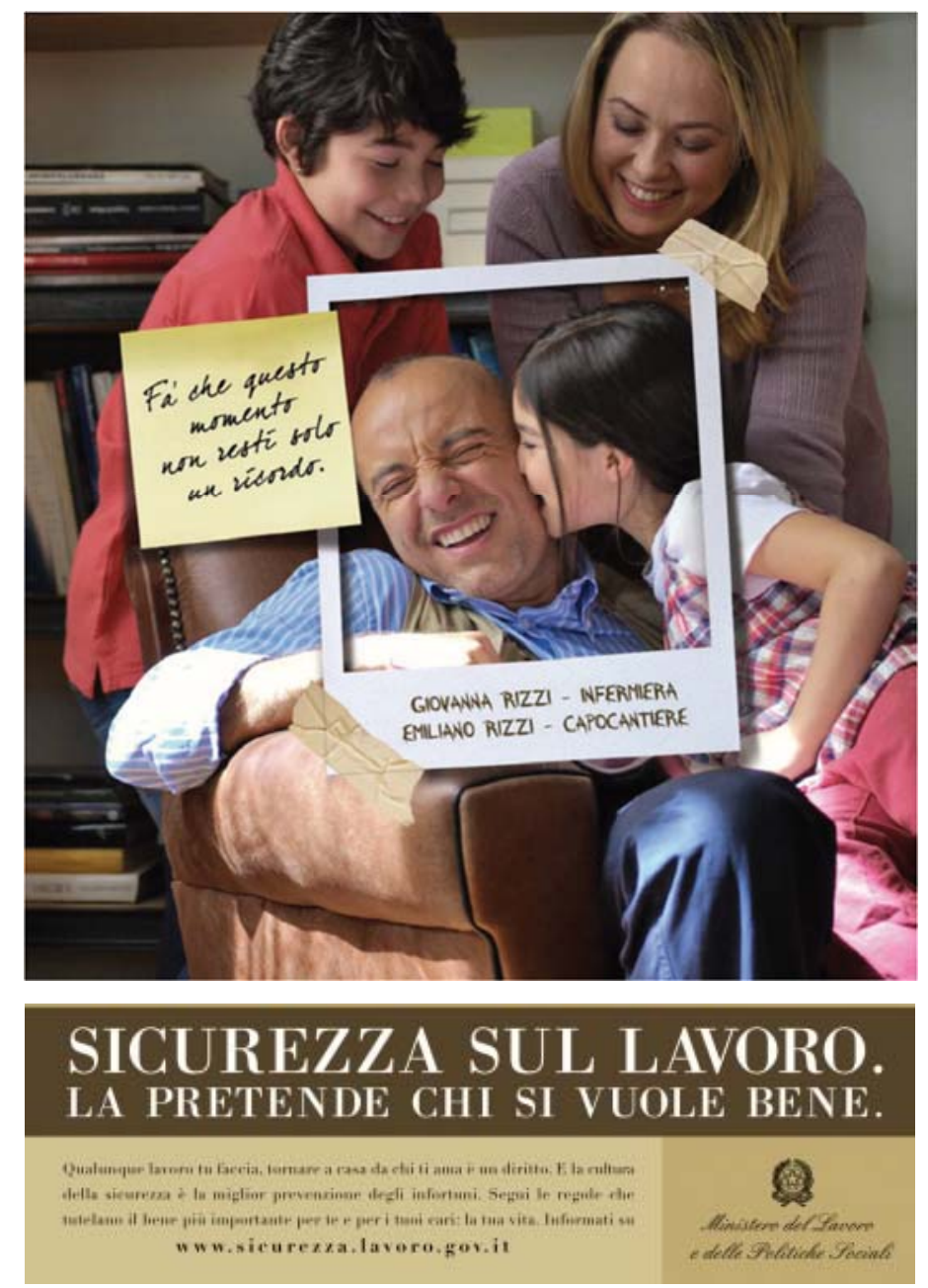

Figura 2. Campanha sobre segurança no trabalho do Ministério do Trabalho e das Políticas Sociais Italiano. 
Essa paradoxal combinação de individualização e de desresponsabilização parece encarnar um estilo de pensamento que opera difusamente no social, os seus sinais podem ser encontrados em outros contextos e situações. O caso da uma decisão de um juiz de Turim ocorrido no mesmo período pode ser interpretado como um sintoma superficial de um processo mais profundo. Em uma sentença referente à morte de um operário de origem albanesa no ambiente de trabalho, de fato, além de "ter atribuído ao operário falecido $20 \%$ de contribuição para a culpa da própria morte", o referido juiz "reconheceu a qualquer um dos genitores residentes na Albânia a indenização de apenas 32 mil euros. Se o operário fosse italiano, seriam aplicadas as novas tabelas em uso junto ao Tribunal de Turim de junho de 2009, segundo as quais para cada parente da vitima seriam reconhecidas somas até dez vezes superiores (entre 150 e 300 mil euros ${ }^{12}$ )". A propriedade descritiva de empregabilidade do referido trabalhador gravou-se definitivamente em seu corpo e na sua história de trabalhador imigrante, demonstrando-se assim muito mais poderosa e performativa do que qualquer dimensão de universalidade que, na sociedade salarial (CASTEL, 1994), se associava ao ingresso em um coletivo que era aquele do ser trabalhador.

O tema da segurança e do bem-estar no trabalho é resultado de uma inscrição em um processo mais geral e receptivo, que se caracteriza como uma paradoxal viragem do projeto de individualização, transformado, de um projeto qualitativo de emancipação e de autodeterminação do sujeito, em um verdadeiro e próprio pré-requisito sistêmico, em um fator funcional dos processos de produção de valor e de verificação da empregabilidade dos indivíduos (BORGHI, 2011). Uma lógica que penetra profundamente o discurso público - prescindindo que este venha enunciado das fronteiras das organizações e sujeitos privados ou públicos - e que emerge não apenas nos exemplos sintomáticos até aqui referidos (a publicidade social do Ministério e a decisão do juiz turinense). Esta lógica parece de fado operar mesmo quando, como já dissemos, a ação pública enuncia formalmente o próprio discurso; como demonstra com precisão Salento (2013), se encontra clara

12 A referida notícia foi retirada do jornal italiano, com sede em Roma, La Repubblica, do dia 25 de outubro de 2010, p. 18. 
evidencia disto no "princípio da responsabilização direta dos trabalhadores (Decreto Lei 81/2008, art. 20), norma "reveladora" de uma abordagem total: se os trabalhadores são chamados a protegerem a si mesmos dos riscos, é porque se deve considerar que os riscos estão legitimamente implicados no modo como o trabalho é desenvolvido".

\section{c. a supremacia do privado: da prevenção da saúde à capacitação}

Um outro sinal a ser rastreado diz respeito a relação entre formas públicas e formas privadas de regulação das condutas individuais. O campo de tensão da argumentação pública sobre trabalho e segurança tem sido fortemente redefinido: em uma sintese extrema, na direção de um enfraquecimento da argumentação sobre a prevenção como processo social e institucional de empoderamento do direito à saúde e de uma crescente conquista hegemônica sobre este mesmo paradigma, via tecnicização e esperticização das bases informativa que o alimentam, do discurso da segurança como objetivo funcional e produtivo. A esse respeito é exemplar o caso da ação da Fiat, referente a um sistema de avaliação do chamado "risco de sobrecarga biomecânica de todo o corpo", denominado "Ergo-Uas". Tentemos agora reconstruir a história desse caso em termos muito esquemáticos.

Em 2004, a Fiat foi condenada a pagar um ressarcimento em consequência de 387 denúncias de doenças profissionais, atribuídas no decorrer da investigação pela introdução, nos anos 90 , de um novo método de organização do trabalho $\mathrm{Tmc}{ }^{13}$. Também em relação a esse episódio, foi colocada em questão (pelo Instituto EPM de Milão) uma metodologia diferente de análise dos postos de trabalho e dos problemas ergonômicos a estes relacionados. Tal método, (denominado Ocra) obteve amplo reconhecimento, tornou-se um padrão internacional no que diz respeito "aos movimentos repetidos dos membros superiores", vindo assim a ser adotado como referência, em conjunto com outros, no mesmo texto legislativo que atualmente regulamenta a questão da segurança do trabalho na Itália ${ }^{14}$. Mas, nos anos sucessivos o corpo gerencial da Fiat impõe a todo o grupo

13 Tempos e Movimentos Relacionados.

14 Decreto Lei 81/08, art. 168, anexo XXIII. 
empresarial a adoção de um novo modelo de organização do trabalho, também esse um padrão internacional, World Class Manufacturing (WCM) (FORTUNATO, 2008; KEAGAN, 2003). Dentro deste padrão encontra-se justamente o método de deteç̧ão de risco Ergo-Uas ${ }^{15}$, que de acordo com uma métrica específica impõe cargas ergonômicas associadas à repartição do ciclo de trabalho de qualquer posto (e a qual se refere um sistema de avaliação de pontuação sobre a base do qual ocorre a referida certificação).

De acordo com um documento muito detalhado, e muito crítico, publicado no site da Direção da Sociedade Nacional dos Operários da Prevenção ${ }^{16}$, de um modo geral "das verificações em curso do trabalho de vários estudiosos especialistas na matéria, pareceria haver uma metódica subestimação do risco de até 40-50 \% do risco real" (OCRA/NIOSH). Além da evidente e denunciada intensificação do ritmo e da saturação dos tempos do trabalho, aquilo que vêm a propósito da introdução dessa metodologia "é a associação de um método de prossecução da qualidade total e um método de detecção do risco em um único modelo organizacional integrado, introduzido e disciplinado em nível no âmbito da empresa e com uma forte centralização, com a utilização de padrões voluntários internacionais" (DI NUNZIO, 2011, p. 45), bem como a subordinação da regulamentação nacional a este mesmo dispositivo de natureza privada. Neste cenário, de um lado, a construção dos dados através dos quais se formam as bases informacionais da segurança é distorcida, segundo o mecanismo de transposição dos fins já referidos anteriormente; do outo, mais globalmente, qualquer fator de capacitação dos trabalhadores e de "democracia na esfera privada" (PALSHAUGEN, 2002) é neutralizada.

No cenário social emergente, no centro do paradigma da prevenção não está a saúde e a remoção dos obstáculos a esta, mas antes o objetivo de manter os sujeitos em nível de "funcionamento", sempre que por estes termos não se pretenda "simplesmente aprender a conviver com doenças ou transtornos que não possam ser curados, mas ser eficientes, independentes,

15 O UAS (Universal Analysis System) é um sistema MTM (Method Time Measurement) "que utiliza agregações de movimentos elementares predeterminados para descrever sequencias de operações elementares. Os tempos assumidos nas agregações são resultados de estudos de casos estatísticos de movimentos elementares MTM-1" (COLOMBINI; OCCHIPINTI; FANTI, 2010, p. 61).

16 Ver. www.snop.it; ver também Tuccino, 2011. 
autônomos” (PITCH, 2008, p. 86). Assim, o par normal/patológico parece substituído,

[...] ou talvez melhor, acompanhado do par funcional/disfuncional, onde o padrão é aquele da capacitação [...] A noção de funcionalidade tem em conjunto naturalidade e engenhosidade, técnica, cultura e tem a vantagem de prestar-se a uma mensurabilidade baseada precisamente sobre o padrão biocultural da capacitação. Este padrão tem como objetivo o 'fazer', não o 'ser', 'fazer' no sentido de ser capaz de funcionar sem ajuda, sem depender de qualquer programa ou serviço (PITCH, 2008, p. 86).

Parece, então, ser possivel detectar, também no contexto do campo da segurança do trabalho, os sinais de uma transformação mais abrangente referente ao paradigma da prevenção. Trata-se de uma progressiva imposição de uma lógica de privatização que se manifesta em pelo menos duas formas concretas. De um lado, como mostramos anteriormente, a segurança torna-se assunto privado, sendo a responsabilidade delegada (sem capacitação, já dissemos) aos indivíduos privados: "a segurança, a exigência que se quer bem”, representada explicitamente isto na campanha publicitária acima referida; Do outo, a segurança torna-se matéria privada, subtraída da regulação pública e reconduzida ao interior do perimetro da regulação organizacional, submetida às normas, aos procedimentos e às práticas (de mensuração, de organização e de certificação) de natureza estritamente privada. Uma regulação privada, entre outras coisas, que não substitui um vazio organizativo, mas sim, se impõe e contrapõe às modalidades de normatização do poder público sobre esta mesma matéria.

\section{Prevenção e subjetivação: as coordenadas da metamorfose}

A linha de tensão que indicamos mais acima (entre uma concepção residual da saúde e uma centrada no direito à saúde) reflete as ambiguidades e as ambivalências do paradigma da prevenção. Os indícios aos quais procuramos captar o sentido, na pesquisa que está na origem da análise aqui desenvolvida, parecem demostrar uma progressiva guinada deste paradigma na direção de especialização, reificação, individualização (no sentido desabilitante acima discutido) e privatização das bases informacionais e de sua lógica operacional. De certo, não temos aqui a intensão de formular uma conclusão, mas antes, de promover novos 
estimulos e de revitalizar linhas de aprofundamentos e de pesquisa, para tal, tentaremos esquematizar com o mapa traçado na figura 3 o quadro interpretativo até aqui proposto.

\section{Eixo da subjetivação}

Assujeitamento

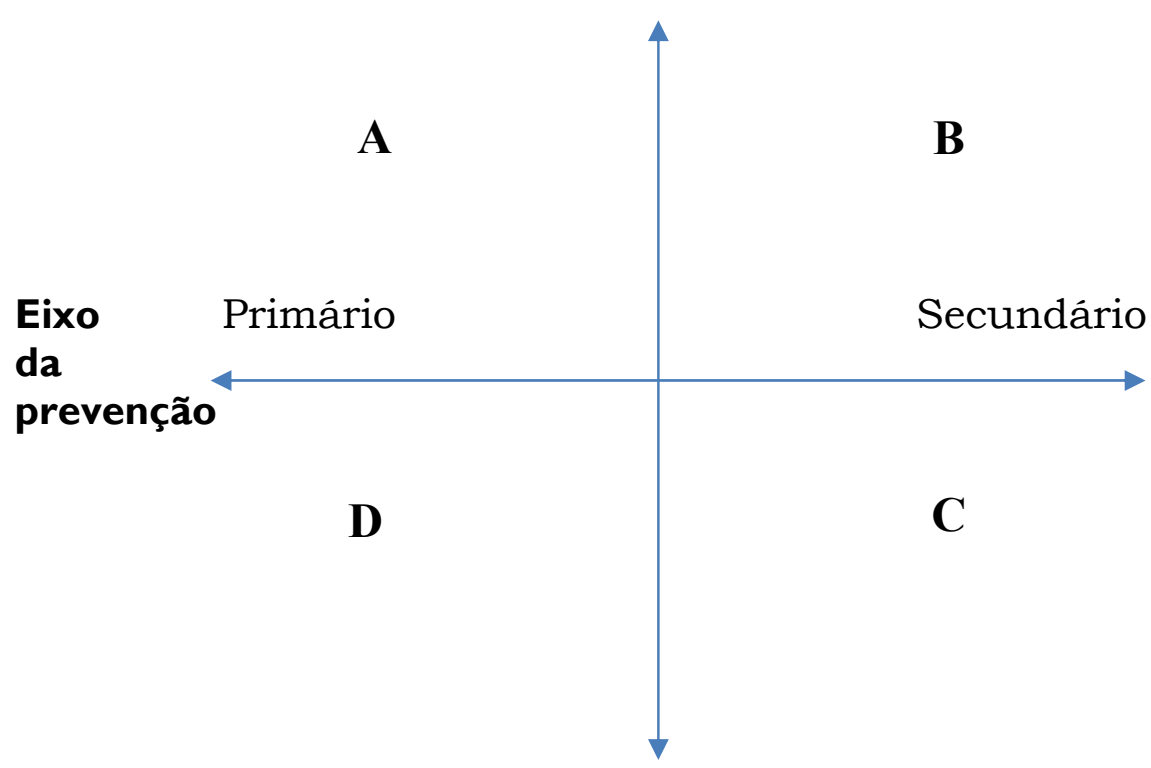

Capacitação

Figura 3. As ambivalências do paradigma da prevenção

Um primeiro fator de ambivalência atua sobre a própria acepção do conceito de prevenção e no plano sobre o qual este deve operar. De um lado, é dada ênfase a prevenção primária, que institui cursos de ação que visam rastrear as causas das patologias no ambiente da vida e do trabalho e identificar a matriz sistêmica; de outro, insiste-se, ao invés disto, na prevenção secundária, que aciona as condutas preventivas e os dispositivos (de vários gêneros: do organizacional ao diagnóstico, farmacológico e genético) que tendem a operar em uma escala individual. Esta segunda abordagem, que prevalece nos desenvolvimentos contemporâneos da genealogia da prevenção, não apenas promove um deslizamento da responsabilidade da dimensão coletiva para a individual, deslizamento doravante profunda e capilarmente disseminado no senso comum; mas, expõe os sujeitos de uma agudização das desigualdades sociais, sempre que 
a capacidade e o poder de intervir como indivíduos no controle dos fatores de risco (ainda que apenas relativamente sobre a segurança e a saúde) não são igualmente distribuídos, ainda menos no contexto do mundo da produção e do trabalho no capitalismo contemporâneo. Uma desigualdade que também se reflete no plano da simples monetarização do risco, como nos evidencia em toda a sua brutalidade o caso da sentença do juiz de Turim sobre a morte do trabalhador de origem albanesa.

Se seguirmos de perto a transformação da qual estamos falando, podemos notar, contudo, que não se trata apenas de individualização, mas, junto a isto, também de privatização da prevenção, isto é, de um conjunto de processos "através do qual aquilo que até pouco tempo faz era tarefa das instituições públicas é impulsionado não apenas no âmbito da responsabilidade individual, mas também no do mercado, do voluntariado, do privado-social" (PITCH, 2008, p. 56). O "mercado impróprio" das isenções, o conjunto do mercado da segurança composto por consultorias, empresas de certificação e de aprovação, adoções de marcas e padrões de natureza privada, exposições, publicidade, formação e assim por diante, oferecem a tal propósito um verdadeiro universo social que poderia ser investigado em si mesmo. Lançando os olhos sobre a sociedade em seu conjunto, damo-nos conta que se trata de um processo generalizado nos mais diversos âmbitos nos quais o paradigma da prevenção opera. No seu estudo sobre "política da vida", por exemplo, Rose (2007, p. 11) insiste várias vezes no fato de que o campo médico, terreno chave da implantação do paradigma da prevenção (e da sua transformação), foi profundamente reestruturado nesse sentido, sempre que a prática médica nos países industrializados "foi colonizada e redesenhada pelas exigências de garantias públicas e privadas, e dos seus critérios de reembolso e do seu tratamento da saúde e da doença, como se não fosse outra coisa senão um cálculo de rentabilidade empresarial".

Todavia, este eixo de ambivalência e contradição deve ser visto e investigado também em relação ao modo no qual se intersecta com um segundo eixo, aquele que na figura 3 definimos como eixo da subjetivação. Em jogo, nesse caso, estão os processos de produção da subjetividade: a relação entre segurança e trabalho é de fato um dos campos do social (entre 
outros), implicada nas mais gerais e globais transformações dos modos de instituir a si mesmas como sujeitos, isto é, como indivíduos e como corpos. Neste sentido, como referido anteriormente, nos leva a pensar que no âmbito das políticas de segurança do trabalho estão operando alterações complementares "à mudança epistemológica" que Rose identifica em termos de intenso desenvolvimento das "tecnologias de otimização".

Com penetração doravante molecular, os objetivos da maximização e do reforço do funcionamento dos organismos biológicos são eficazmente perseguidos pelas novas tecnologias da vida: estes "não se limitam a curar o dano ou a doença orgânica, nem sequer a melhorar a saúde (...), mas modificam aquilo que significa ser um organismo biológico, tornando possivel reconfigurar - ou esperando torná-lo possivel - os mesmos processos vitais, com o objetivo de maximizar seus funcionamentos e reforçar seus resultados" (ROSE, 2007, p. 17-18). Mas, tais maximizações e reforços foram sempre procurados no passado, aquilo que é novo, entre outros aspectos, é a intensa combinação de personalização e padronização, combinação através que opera, em diversos campos de aplicação, a atual reinterpretação do paradigma da prevenção. Personalização e padronização porque não se trata de processos que individualizam no sentido de conferir poder a agencia do sujeito, intensificando-lhe as capacidades e a capacidade de voz; ao contrário, eles operam, e assim o fazendo conferem a ele um papel sempre mais relevante, sobre o plano da personalidade funcional, nesse sentido, padronizada (trabalhador e/ou consumidor que seja), e das performances que esta deve uma vez ou outra estar em condições de exprimir no modo mais eficiente possivel. Com uma linguagem diferente, podemos falar "abstrações reais" (força de trabalho, consumidor, como figuras abstratamente universais, conforme a lógica do processo de valorização e a "cadeia de valor" através da qual estas se desenvolvem) que se impõem com força inédita sobre a heterogeneidade e multiplicidade das formas de vida (e de trabalho vivo); se impõem, mas também se colidem, entram em atrito, entram em contradição com formas que mantém a própria autonomia e especificidades, opõem resistência, alimentam a crítica (TSING, 2009; BORGHI; MEZZANDRA, 2011). 
Nos termos destes procedimentos de personalização funcional: "o humano não se torna menos biológico, mas ainda mais biológico" (ROSE, 2007 , p. 20). Assim como ocorre geralmente no paradigma da prevenção, a respeito do qual se observa uma progressiva "ao puro dado biológico" dos sujeitos e de seus corpos (PITCH, 2008, p. 66), do mesmo modo no campo da segurança observa-se uma crescente hegemonia das práticas relativas aos sujeitos e aos corpos enquanto funções reificadas por meio de saberes específicos especializados (de tipo predominantemente médico, engenherístico e psicológico), no qual são em todos os casos cortados os enraizamentos sociais, políticos, de gênero, etc. Processos (de naturalização e renaturalização) que ocorrem através da extensão também neste âmbito da experiência, daquilo que Desrosieres (2011) definiu como "governo através dos números". O paradigma da prevenção é assim objeto de uma "cientificização" das bases informacionais e dos conhecimentos referentes a definição do que significa "ser seguro" (BORGHI; GRANDI, 2013) e de como é possivel operar tal definição, que podemos rastrear (entre outras coisas) na depreciação e na marginalização de todas aquelas formas de conhecimento (centrais, nós vimos, para a fase de institucionalização do paradigma da prevenção) que não ascendem ao estatuto de saberes científicos $\mathrm{e}$ especializados; na crescente restrição das bases informacionais das politicas e do discurso público apenas os saberes formalizáveis e quantificáveis (vejam-se, por exemplo, os casos do "stress relacionado ao trabalho ou aquele do método Ergo-Uas"). Na introdução de uma rígida distinção sujeito/objeto do conhecimento, sempre que - como vimos por meio de vários exemplos - as competências daqueles que vivenciam os problemas diretamente são frequentemente marginalizadas ou completamente eliminadas da possibilidade de intervir (tanto de modo individual quanto e ainda mais de modo coletivo) sobre os dispositivos (padrões, certificações, modelos de formação) destinados ao tratamento dos problemas enfrentados. Nos termos aos quais se refere Alain Supiot (2011, p. 59) em termos gerais:

A governança dos números tende [...] à autorregularão das sociedades humanas. Ela se baseia sobre a faculdade do cálculo, a saber, sobre uma operação de quantificação (reconduzir seres e situações diferentes a uma mesma unidade de consideração) e de programação dos comportamentos (através de técnicas de 
comparação das performances: benchmarking, ranking, etc.). Sobre o império da governança a normatividade perde a própria dimensão vertical: não se trata mais de uma lei que transcende os fatos, mas de inferir a norma da medida dos fatos.

Aqui, mais uma vez faz-se pertinente a análise de Rose (2007, p. 27), quando destaca que o cerne da mudança em curso diz respeito à éticopolítica, vale dizer, ao âmbito dos "esforços para modelar a conduta dos seres humanos agindo sobre os seus sentimentos, sobre suas crenças e seus valores - resumindo, agindo eticamente". Em jogo está a materialidade própria dos corpos e do processo de subjetivação, a partir do momento que se trata da política que apresenta como objeto "o modo no qual devemos nos comportar apropriadamente em relação a nós mesmos e com a nossa responsabilidade pelo futuro" (ROSE, 2007, p. 27). O discurso público em matéria de segurança do trabalho (a partir não apenas de sua condensação em dispositivos de tipo legislativo, mas também de tipo organizacional e de regulamentação privada) e o conjunto das bases informacionais dos quais se aproveita (e que contribui para produzir) é parte dessa transformação de fundo, como a nossa análise procurou demostrar: é sobre esse plano que "se forma o meio social em cujo âmbito coagulando-se novas formas de autoridade" (ROSE, 2007, p. 27) e que se deve, portanto, continuar a ser investigado.

\section{Referências Bibliográficas}

ACCORNERO, Aris. La parabola del sindacato: ascesa e declino di una cultura. Bologna: Il Mulino, 1992.

APPADURAI, Arjun. Le aspirazioni nutrono la democrazia, Milano: Et al, 2011.

BIFULCO, Lavinia. Che cos'è una organizzazione. Roma: Carocci, 2002.

BIFULCO, Lavinia; MOZZANA, Carlotta. La dimensione sociale delle capacità: fattori di conversione, istituzioni e azione pubblica, Rassegna Italiana di Sociologia, v. 52, n. 3, 2011.

BOLOGNINI, Bruno. La formazione nelle organizzazioni. Roma: Carocci editore, 2012.

BONVIN, Jean-Michel, FAVARQUE, Nicolas. What informational basis for assessing job-seekers? Capabilities vs. Preferences. in Review of Social Economy, v. 63, n. 2, 2005. 
BORGHI, Vando. Activation and the emerging regimes of justification in the European welfare capitalism: notes from the Italian perspective, paper per Second ASPEN / ETUI - REHS conference, March 20-21, 2009, Masaryk University, Brno, Czech Republic.

- La presa della rete: tendenze e paradossi del novo spirito del capitalism. Rassegna Italiana di Sociologia, v. 52, n. 3, 2011.

. Sociologia e critica nel capitalismo reticolare. Risorse ed archive per una proposta, Rassegna Italiana di Sociologia, v. 52, n. 3, 2012.

BORGHI, Vando; GRANDI, Stefano. Cosa vuol dire essere sicuri? Pratiche e rappresentazioni della sicurezza del lavoro, Sociologia del lavoro, n. 130, 2013.

BORGHI, Vando; MEZZADRA, Sandro. In the Multiple Shadows of Modernity. Strategies of Critique of Contemporary Capitalism, Saarbrücken: Lambert Academic Publishing, 2011.

BORGHI, Vando; RIZZA, Roberto. L'organizzazione sociale del lavoro,. BORGHI, Vando; Van BERKEL, Rik. (eds.), New forms of governance in labour-market and activation policies, II, International Journal of Sociology and Social Policy, v. 27, n. 9/10, 2007.

BORGHI, Vando; van BERKEL, Rik. (eds.), New forms of governance in labour-market and activation policies, I, International Journal of Sociology and Social Policy, v. 27, n. 7/8, 2007.

BOURDIEU, Pierre. Lezione sulla lezione, Genova: Marietti, 1991.

CARNEVALE, Francesco; BALDASSERONI, Alberto. Mal da lavoro: storia della salute dei lavoratori. Roma-Bari: Laterza, 1999.

CASTEL, Robert. Problematization as a Mode of Reading History. In: GOLDSTEIN, Jan. Foucault and the Writing of History, Oxford: Blackwell, 1994.

CLOT, Yves. L'igienismo contro il lavoro di qualità? In: MAGGI, Bruno, RULLI, Giovanni. Prevenzione nei luoghi di lavoro e valutazione dello stress in Francia e in Italia. Bologna: Tao Digital Library, 2011. Acesso em 20 de março de 2012. Disponivel em: al http:/ /amsacta.unibo.it/3061/

COLOMBINI, Daniela; OCCHIPINTI, Enrico; FANTI, Michele, Il metodo OCRA per l'analisi e la prevenzione del rischio da movimenti ripetuti: manuale per la valutazione e la gestione del rischio. Milano: Franco Angeli, 2010 .

COSMACINI, Giorgio. Storia della medicina e della sanità nell'Italia contemporânea. Roma-Bari: Laterza, 1994. 
De LEONARDIS, Ota. Vedere il potere. Prefácio de SENNETT, Richard. Autorità. Subordinazione e insubordinazione: l'ambiguo vincolo tra il forte e il debole. Milano: Bruno Mondadori, 2006.

E se parlassimo un po' di politica? In: APPADURAI, Arjun. Le aspirazioni nutrono la democrazia, Milano: Et al. Edizioni, 2011.

De LEONARDIS; Ota. DERIU, Marco. Il futuro nel quotidiano: studi sociologici sulla capacità di aspirare. Milano: Egea, 2012.

DESROSIERES, Alain. Buono o cattivo? Il ruolo del numero nel governo della città neoliberale In: Rassegna Italiana di Sociologia, v. 52, n. 3, 2011.

Di NUNZIO, Daniele. Tendenze nei modelli organizzativi, sistemi di gestione della salute e sicurezza e benessere dei lavoratori. Questione giustizia, n. 2, 2012.

Rischi sociali e per la salute: le condizioni di lavoro dei giovani in Italia. Roma: Ediesse, 2011.

FLECK, Ludwick. Genesi e sviluppo di un fatto scientifico: per una teoria dello stile e del coletivo di pensiero. Bologna: Il Mulino, 1983.

FORTUNATO, Vincenzo. Ripensare la FIAT di Melfi: condizioni di lavoro e relazioni industriali nell'era del World Class Manufacturing. Roma: Carocci, 2008.

GIULLARI, Barbara. Lavoro, occupabilità e trasformazioni del sistema formativo nella società della conoscenza. Milano: FrancoAngeli, 2006.

Tra lavoro e conoscenza. Una introduzione, In: Tra conoscenza e lavoro: scenari e strategie nel rapporto tra formazione e occupazione. Sociologia del lavoro, n. 120, 2010.

GIULLARI, Barbara. RUFFINO, Marco. Descrivere, classificare, contare: produzione, utilizzo e criticità delle rappresentazioni del lavoro. In:

Descrivere, classificare, contare: le rappresentazioni del lavoro nello spazio pubblico. Sociologia del lavoro, n. 129, 2012.

GIULLARI, Barbara, RIZZA, Roberto, SANSAVINI, Mila. Il campo della sicurezza del lavoro, In: BORGHI, Vando; De LEONARDIS; Ota., PROCACCI, Giovanna. La Ragione Politica 2: I discorsi dele politiche. Napoli: Liguori Editore, 2013.

GOSETTI, Giorgio. Lavoro frammentato, rischio diffuso: lavoratori e prevenzione al tempo dela flessibilità. Milano: Franco Angeli, 2012.

ILLICH, Ivan et al. Esperti di troppo: il paradosso delle professioni disabilitanti, Trento: Erickson, 2008.

MORANDI, Bruno. La merce che discute. Milano: Feltrinelli, 1978. 
ODDONE, Ivar; BRIANTE, Giovanni, Esperienza operaia e psicologia del lavoro, Roma: Editrice sindacale italiana, 1974.

PERULLI, Paolo. Il dio contratto: origine e istituzione della società contemporanea. Torino: Einaudi, 2011.

PITCH, Tamar. La società della prevenzione. Roma: Carocci, 2008.

PALSHAUGEN, Ǿyvind. Discourse democracy at work. On public sphere in private enterprises. In: Concepts and transformations, v. 7, n. 2, 2002.

PÖRSKSEN, Uwe. Parole di plastica: la neolingua di una dittatura internazionale, L’Aquila: Textus edizioni, 2011.

POWER, Michael. La società dei controlli: rituali di verifica. Torino: Edizioni di Comunità, 2002.

RIGHI, Maria Luisa. Le lotte per l'ambiente di lavoro dal dopoguerra ad oggi. Studi Storici. v. 33, n. 2/3, 1992.

ROSE, Nikolas. The politics of life itself: biomedicine, power, and subjectivity in the twenty-first century, Princeton: Princeton University Press, 2007.

SALAIS, Robert. Le convenzioni come strumenti di policy: 1'Europa e la 'decostruzione' dela disoccupazione. In: GIULLARI, Barbara. e RUFFINO, Marco. Descrivere, classificare, contare: le rappresentazioni del lavoro nello spazio pubblico, Sociologia del lavoro, n. 129, 2012.

SALENTO, Angelo. Concezioni di organizzazione e regolazione della sicurezza del lavoro. In: BORGHI, Vando; GRANDI Stefano. (eds.). Cosa vuol dire essere sicuri? Pratiche e rappresentazioni della sicurezza sul lavoro, Sociologia del lavoro, n. 130, 2013.

SCOTT, William Richard. Le organizzazioni, Bologna: Il Mulino. 1992.

SEN, Amartya. L'idea di giustizia. Milano: Mondadori, 2010.

SUPIOT, Alain. Lo spirito di Filadelfia: giustizia sociale e mercato totale. Milano: Et al., 2011.

TRENTIN, Bruno. Relazione introduttiva al XV congresso nazionale della Fiom-Cgil, In: Da sfruttati a produttori, lotte operaie e sviluppo capitalistico dal miracolo economico alla crisi. Dedalo, Bari, 1977.

TSING, Anna. Supply Chains and the Human Condition. Rethinking Marxism: A Journal of Economics, Culture \& Society, v. 21, n. 2, 2009.

TUCCINO, Francesco. Il nuovo modello di organizzazione del lavoro in Fiat: il sistema Ergo-Uas. Gli effetti sulla salute e sulle condizioni di lavoro. Economia \& Lavoro, v. 45, n. 2, 2011. 
Van BERKEL, Rik. WALKENBURG B. (eds.), Making it personal: individualising activation services in the EU, Bristol: Policy, 2007.

VISVANATHAN, Shiv. The search for cognitive justice, 2009. Disponivel em: www.india-seminar. com/2009/597/597_shiv_visvanathan.htm.

WEICK, Karl. Senso e significato nell'organizzazione: alla ricerca delle ambiguità e dele contraddizioni nei processi organizzativi. Milano: Raffaello Cortina, 1997. 